Supporting Information

\title{
Bulk and interfacial contributions to stabilization of cyclodextrin-based emulsions mediated by bacterial cellulose
}

Jie $\mathrm{Hou}^{1,2}$, Cailing $\mathrm{Chu}^{1,2}$, Hua-Neng $\mathrm{Xu}^{1,2 *}$, Lianfu Zhang ${ }^{2}$

${ }^{1}$ State Key Laboratory of Food Science and Technology, Jiangnan University, 1800

Lihu Avenue, Wuxi, Jiangsu 214122, People's Republic of China

${ }^{2}$ School of Food Science and Technology, Jiangnan University, 1800 Lihu Avenue, Wuxi, Jiangsu 214122, People's Republic of China

*To whom correspondence should be addressed. E-mail: hnxujnu@163.com

Number of pages: 2

Number of figures: 1

Number of tables: 0

\section{Contents:}

Figure S1: AFM images of bacterial cellulose. S2 


\section{Bacterial Cellulose Characterization by AFM}

Bruker Dimension Fast Scan AFM system in tapping model was used to scan the micro-morphology of bacterial cellulose $(\mathrm{BC})$. The $\mathrm{BC}$ was diluted to $0.001 \%(\mathrm{w} / \mathrm{v})$ and then treated with ultrasound for $20 \mathrm{~min}$ in $500 \mathrm{w}$ to obtain an unfolded $\mathrm{BC}$ suspension. $10 \mu \mathrm{L}$ of this suspension was dropped on a fresh mica surface and dried at room temperature. NanoScope Analysis software was applied to analyze the diameter and height of the bacterial cellulose.

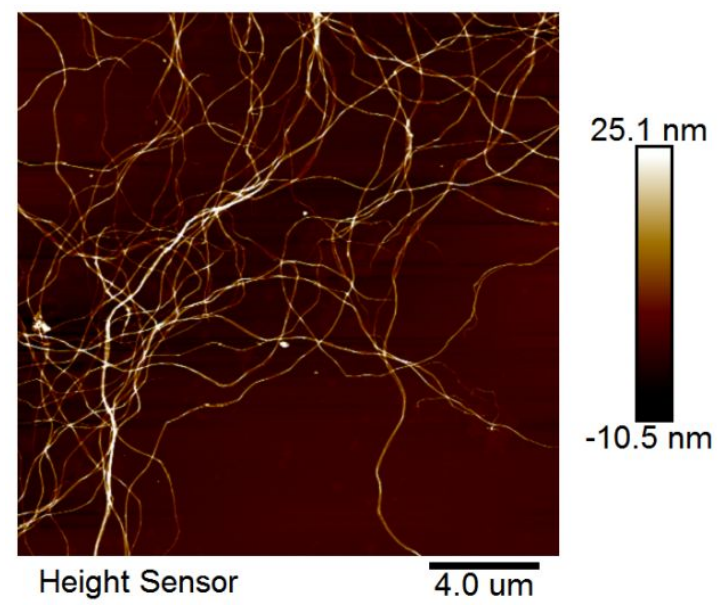

Fig. S1 AFM images in tapping model of $0.001 \mathrm{wt} \%$ bacterial cellulose. 